\title{
Management of Anaemia of Chronic Disease: Beyond Iron-Only Supplementation
}

\author{
Evasio Pasini ${ }^{1}$, Giovanni Corsetti ${ }^{2}{ }^{*}$ (D) Claudia Romano ${ }^{2}$, Roberto Aquilani ${ }^{3}$, Tiziano Scarabelli ${ }^{4}$, \\ Carol Chen-Scarabelli ${ }^{5}$ and Francesco S. Dioguardi ${ }^{6}$ (D)
}

1 Cardiac Rehabilitation Division, Scientific Clinical Institutes Maugeri, IRCCS Lumezzane, Lumezzane, 25065 Brescia, Italy; evpasini@gmail.com

2 Division of Human Anatomy and Physiopathology, Department of Clinical and Experimental Sciences, University of Brescia, 25065 Brescia, Italy; cla300482@gmail.com

3 Department of Biology and Biotechnology, University of Pavia, 27100 Pavia, Italy; dottore.aquilani@gmail.com

4 Center for Heart and Vessel Preclinical Studies, St. John Hospital and Medical Center, Wayne State University, Detroit, MI 48202, USA; tscarabelli@hotmail.com

5 Division of Cardiology, Richmond Veterans Affairs Medical Center (VAMC), Richmond, VA 23249, USA; chenscarabelli@hotmail.com

6 Department of Internal Medicine, University of Cagliari, 9128 Cagliari, Italy; fsdioguardi@gmail.com

* Correspondence: giovanni.corsetti@unibs.it; Fax: +39-030-3717486

Citation: Pasini, E.; Corsetti, G.;

Romano, C.; Aquilani, R.; Scarabelli, T.; Chen-Scarabelli, C.; Dioguardi, F.S. Management of Anaemia of Chronic Disease: Beyond Iron-Only Supplementation. Nutrients 2021, 13, 237. https://doi.org/10.3390/nu 13010237

Received: 7 December 2020 Accepted: 12 January 2021 Published: 15 January 2021

Publisher's Note: MDPI stays neutral with regard to jurisdictional clai$\mathrm{ms}$ in published maps and institutional affiliations.

Copyright: (C) 2021 by the authors. Licensee MDPI, Basel, Switzerland. This article is an open access article distributed under the terms and conditions of the Creative Commons Attribution (CC BY) license (https:// creativecommons.org/licenses/by/ $4.0 /)$.

\begin{abstract}
Chronic diseases are characterised by altered autophagy and protein metabolism disarrangement, resulting in sarcopenia, hypoalbuminemia and hypo-haemoglobinaemia. Hypohaemoglobinaemia is linked to a worse prognosis independent of the target organ affected by the disease. Currently, the cornerstone of the therapy of anaemia is iron supplementation, with or without erythropoietin for the stimulation of haematopoiesis. However, treatment strategies should incorporate the promotion of the synthesis of heme, the principal constituent of haemoglobin $(\mathrm{Hb})$ and of many other fundamental enzymes for human metabolism. Heme synthesis is controlled by a complex biochemical pathway. The limiting step of heme synthesis is D-amino-levulinic acid (DALA), whose availability and synthesis require glycine and succinil-coenzyme A (CoA) as precursor substrates. Consequently, the treatment of anaemia should not be based only on the sufficiency of iron but, also, on the availability of all precursor molecules fundamental for heme synthesis. Therefore, an adequate clinical therapeutic strategy should integrate a standard iron infusion and a supply of essential amino acids and vitamins involved in heme synthesis. We reported preliminary data in a select population of aged anaemic patients affected by congestive heart failure (CHF) and catabolic disarrangement, who, in addition to the standard iron therapy, were treated by reinforced therapeutic schedules also providing essential animo acids (AAs) and vitamins involved in the maintenance of heme. Notably, such individualised therapy resulted in a significantly faster increase in the blood concentration of haemoglobin after 30 days of treatment when compared to the nonsupplemented standard iron therapy.
\end{abstract}

Keywords: chronic diseases; iron deficiency; haemoglobin; anaemia; aminoacids; rehabilitation

\section{Introduction}

Noncommunicable diseases account for 38 million deaths per year, according to the World Health Organization [1]. Of these deaths, chronic diseases (CD) constitute a major cause of mortality. The most common CD include congestive heart failure (CHF), senescence, cancer, chronic obstructive pulmonary disease (COPD), diabetes, arthritis, asthma and some viral diseases such as hepatitis $C$ and acquired immunodeficiency syndrome [2].

All CD are characterised by a hypercatabolic syndrome due to low-grade inflammation (caused by specific molecules such as cytokine, hormones, etc.), which induces metabolic alterations and muscular and globular protein disarray. An unmatched autophagy activity 
ensues, clinically resulting in sarcopenia, hypoalbuminemia and hypo-haemoglobinemia (otherwise known as anaemia) [3,4]. Among the globular proteins, haemoglobin $(\mathrm{Hb})$ is one of the most readily measureable in the blood.

Mounting experimental and clinical evidence has demonstrated that both anaemia and iron deficiency (ID) are present in patients with $C D$, resulting in the significant limitation of therapeutic rehabilitative strategies such as rehabilitation programs, thereby worsening the prognosis of these patients [5-7]. Studies suggest concomitant roles for inflammation and autophagy bridged to the subsequent protein disarrangement [8].

Gut dysbiosis, nutritional imbalance (malnutrition) with dysgeusia and, most importantly, ID with or without renal dysfunction capable of reduced erythropoietin-mediated erythropoiesis, are responsible for anaemia in CHF patients [5,9]. Consequently, iron supplementation, with or without the addition of erythropoietin, is the most commonly recommended therapeutical approach to CHF-mediated anaemia [10].

Based on the current biochemical knowledge, the pathogenesis of anaemia in $\mathrm{CD}$ (including CHF) should be considered in its entirety [11]. Although heme is the principal biochemical constituent of haemoglobin, with ID contributing partially to the anaemia in $\mathrm{CD}$, one of the additional contributory factors in anaemia includes the impaired synthesis of the tetrapyrrolic rings to which iron binds, thereby facilitating the metabolic function of heme, a hemoprotein. The production of D-amino-levulinic acid (D-ALA), the limiting step in the synthesis of the heme ring, warrants significant consideration. D-amino-levulinic acid (D-ALA) is derived from one amino acid, glycine, and Kreb's cycle intermediate succinylcoenzyme A (CoA) [12]. Therefore, an adequate treatment of anaemia in CD necessitates the incorporation of a standard iron infusion, along with the supplementation of essential amino acids (EAAs) and vitamins involved as precursors or cofactors in heme synthesis.

In order to demonstrate the importance of the molecules involved in the synthesis of haemoglobin, we first provide a review of the main events necessary for the synthesis and the functions of heme and the roles of the molecules centrally involved in heme synthesis. Following the review, we present a clinical study designed to evaluate the effects of an integrated supplementation with iron and the molecules involved in the synthesis of haemoglobin in anemic patients with evident deficiencies of these molecules.

\subsection{Iron and Heme}

Iron ( $\mathrm{Fe})$, a requisite metal in almost all biological systems, is necessary for numerous critical processes, such as DNA synthesis, heme and iron-sulfur cluster synthesis, etc. Therefore, the cellular regulation of the iron concentration is essential for the maintenance of normal physiology [13].

About $70 \%$ of the body's iron is found in the red blood cells as a component of haemoglobin and in the muscle cells as myoglobin. Iron is also a crucial component of a very large class of metalloproteins containing heme-hence the name, hemoproteins.

Heme is an organic, ring-shaped molecule consisting of an iron ion coordinated to four pyrroles, which are small, pentagon-shaped molecules with four carbons and one nitrogen, which, together, form an iron-binding tetrapyrrole, called a porphyrin (Figure 1). Thus, heme is an iron-binding porphyrin [11]. Interestingly, iron plays a balanced attractive force interacting with the nitrogen molecules of heme; thus, the electrons stay balanced, and the global molecule remains stable.

There are four different forms of heme in nature: heme- $\mathrm{A},-\mathrm{B},-\mathrm{C}$ and $-\mathrm{O}$; they influence the functions of the molecules in which heme is present. Although heme-B is the most common form, heme-A and - $\mathrm{C}$ are present in many molecules. The biochemical behaviors of the most common heme groups are regulated by differences of the functional groups in the side chains bound to carbons 3,8 and 18 [11]. 


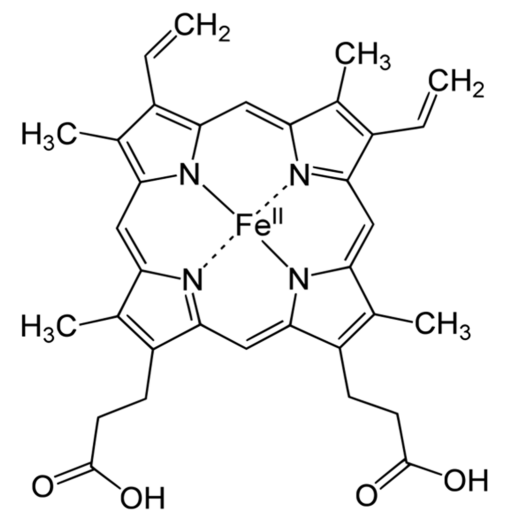

Figure 1. Haemoglobin structure.

\subsection{The Synthesis of Heme}

Porphyrin synthesis, the biochemical pathway from which heme is derived, begins with the synthesis of D-amino-levulinic acid (D-ALA), which is also the limiting step in heme synthesis [12].

D-ALA originates from the amino acid (AA) glycine and from the Kreb's cycle intermediate succinyl-CoA, which, in turn, is derived by $\alpha$-ketoglutarate or from the metabolism of the EAAs isoleucine, methionine, threonine or valine. Interestingly, D-ALA synthesis occurs inside the mitochondria and depends on the activity of an enzyme named ALA-synthase, which is negatively regulated by glucose and the heme concentration. Importantly, inhibition of the enzyme is also dependent on the stability and availability of its mRNA in the mitochondria. Notably, AAs are the sole sources of carbon and nitrogen atoms provided to D-ALA, demonstrating the narrow link between the metabolism of the AAs and the energetic metabolism.

Released from the mitochondria, two D-ALA molecules are condensed to form porphobilinogen in the cytoplasm. This synthetic reaction continues until the formation of coproporphyrinogen-III, which is transported back inside the mitochondrial matrix and converted into protoporphyrin-IX. The enzyme ferrochelatase then inserts an iron atom, forming one heme molecule, which is then shuttled to the cytoplasm, where it is available for the synthesis of heme-based molecules [14]. The process of heme synthesis is illustrated in Figure 2.

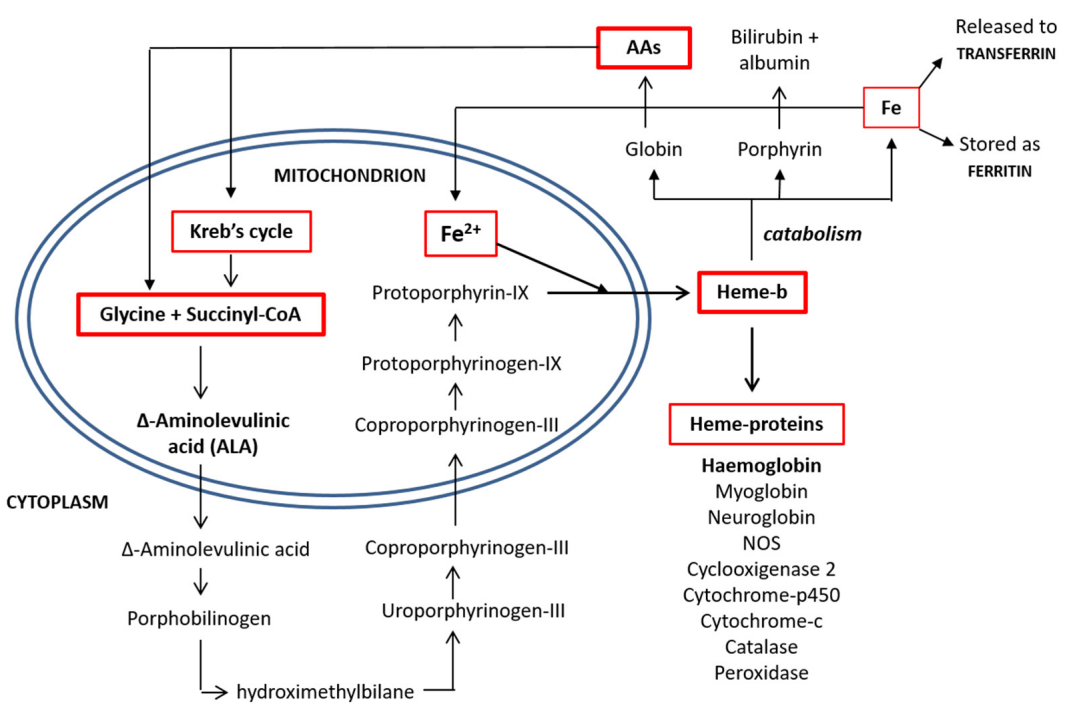

Figure 2. Heme synthesis and degradation pathways. AAs: amino acids and CoA: coenzyme A. 


\subsection{Functions of Heme}

Heme and hemoproteins have many biological functions. The presence of an iron atom serves as a source of electrons during electron transfer or redox chemistry, thereby giving heme the ability to transport biatomic gases and to exert a chemical catalysis requiring an electron transfer.

Hemoproteins participate in many diverse biological actions (such as oxygen transport) fundamental for life. Indeed, although haemoglobin and myoglobin are the two best-known hemoproteins, other important, although often overlooked, enzymes that belong to hemoproteins include cytochrome p450s, cytochrome-c oxidase, cyclooxygenase 2, catalase, peroxidases and endothelial nitric oxide synthase. In addition, as part of the electron transport chain, hemoproteins also enable an electron transfer. A change in the iron content affects important cell survival systems, illustrating that heme is not only pivotal for oxygen transport but also plays a fundamental role in other important metabolic pathways, such as energy production, the transformation of many molecules, the detoxification of aggressive molecules such as as oxygen-free radicals, the regulation of inflammation and/or vascular tone and blood coagulation [11].

\subsection{Other Molecules Involved in Heme Synthesis}

$\mathrm{CD}$, especially if associated with qualitative malnutrition, induces a hypercatabolic state and consequent protein disarrangement, which can precipitate the development of anaemia secondary to a reduction in haemoglobin. A schematic representation of this link is proposed in Figure 3. Independently from iron, other molecules that are strictly related to heme synthesis include:

Vitamin B1. Its pyrophosphate ester, thiamine diphosphate (TPP), is a cofactor for enzymes that catalyse alpha-keto acids of molecules involved in the Kreb's cycle and its intermediary metabolism [15].

Vitamin B6. It cocatalyses reactions related to the anabolism and catabolism of AAs, facilitating the reactions of transamination. Interestingly, it is involved in protein folding and interacting with the folate cycle. In addition, vitamin B6 is a scavenger of free oxygen radicals [16].

Vitamin B9 (Folate). It is a cofactor of many enzymes involved in the redox reactions and transfer of the AA one-carbon unit (DNA methylation) [17].

Vitamin D. It has anti-inflammatory properties, reducing circulating cytokines (interleukin 6 (IL-6) and IL-1B) that counteract catabolism and autophagy. It stimulates the synthesis of anabolic molecules (such as fibroblast growth factor-23 (FGF-23)) and increases red blood cell lifespans. In addition, it modulates hepcidin, a molecule responsible for the regulation of iron metabolism [18].

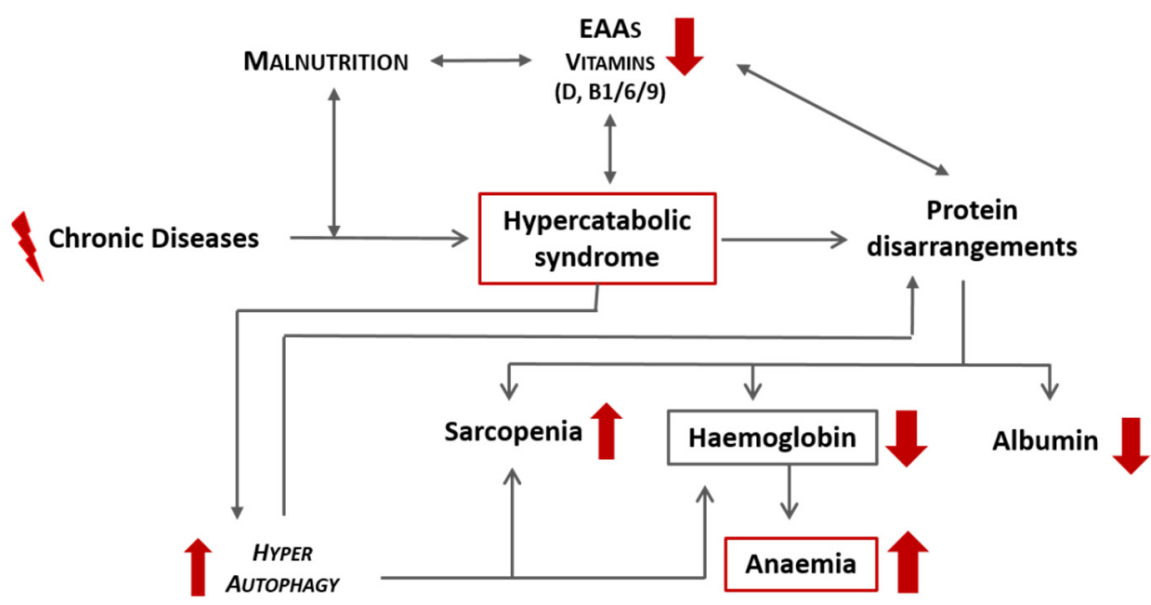

Figure 3. Schematic representation of the effects of chronic diseases and malnutrition on the onset of anaemia. EAAs: essential amino acids. 
Amino Acids. Hemoproteins (as haemoglobin), consisting of heme (as the metabolically active part) and the surrounding proteins (as globin molecules), contain a large number of different AAs. Previous studies have demostrated that the administration of mixtures of free EAAs tailored to match the human metabolic process were able to improve anabolism, the aerobic metabolism and mitochondrial neogenesis [19,20]. Rapidly absorbed, this mixture contains appropriate stoichiometric amounts of all EAAs that can be converted into nonessential AAs (NEAAs), such as glycine [21]. Moreover, the EAAs mixture contains: (a) L-leucine, which modulates the enzyme mTORC1 involved in haemoglobin production, and (b) histidine, which stabilises bound $\mathrm{O}_{2}$ and, placed in particular positions, acts as a gate, allowing ligands entry into both haemoglobin subunits [22,23]. Therefore, histidine, essential in globin synthesis and erythropoiesis, has also been implicated in the enhancement of iron absorption from human diets. Furthermore, histidine has already been proven to be effective both in improving the antianaemic efficiency and limiting the damages resulting from an iron overload and oxidative stress caused in chronic kidney disease (CKD) [24]. Conversely, beta-alanine supplementation would impair protein synthesis by reducing the histidine concentration and availability [25].

In light of these considerations, the provision of the molecules involved in the synthesis of heme and haemoglobin is essential, even more so if patients are malnourished.

\section{Methods}

Based on the aforementioned fundamental biochemical knowledge, and in observation of "good medical practice" (www.gmc-uk.org), we conducted a controlled clinical trial that integrated personalised standard therapy with an iron infusion, along with the administration of specialised mixtures rich in free EAAs [21] and vitamins (B1, B6, B9 and D) to treat heme synthesis deficiency in a cohort of select elderly female patients $(n=15$; ages $78.3 \pm 8.5$ years old (y.o.) ) with signs and/or symptoms of CHF with a preserved ejection fraction (HFpEF). Written informed consent was obtained; ethical approval was not required under local legislation. The inclusion criteria were: (1) anaemia $(\mathrm{Hb}>8.5 /<11.5 \mathrm{mg} / \mathrm{dL}) ;(2)$ symptoms and signs of stable CHF for at least 3 months on a standard medical therapy with a beta-blocker, diuretics, ACE-inhibitor or ARB (Angiotensin Receptors Blockers); (3) protein disarrangement (serum abumin $<3.5 \mathrm{~g} / \mathrm{dL}$ ) but a normal body mass index (BMI) (range $>23<30$ for people over 65 y.o.); (4) iron deficiency (plasma iron $<50 \mu \mathrm{g} / \mathrm{dL}$, ferritin $<100 \mathrm{ng} / \mathrm{mL}$ or serum ferritin within the range 100-299 $\mu \mathrm{g} / \mathrm{dL}$ when the transferrin saturation is $<20 \%$ ); (5) inflammation (by C-reactive protein $(\mathrm{CRP})>5 \mathrm{mg} / \mathrm{dL}$ ) and (6) vitamin $\mathrm{D}$ and/or folate lower than the normal ranges of the serum concentrations (15.2-90.1 pg/mL and $>3.00 \mathrm{ng} / \mathrm{mL}$, respectively).

In addition to the low haemoglobin concentration, since these patients had serum albumin and vitamin D and/or folate levels below the minimum, they were treated, according to good medical practice standards, for 30 days with a daily intravenous administration of $2 \mathrm{~mL}$ of ferric carboxymaltose containing $100 \mathrm{mg}$ of elemental iron $(50 \mathrm{mg} / \mathrm{mL})$, integrated with an oral administration of $4 \mathrm{~g}$ of a specific free AAs mixture rich in essential ones $(84 \%)$ containing $0.15 \mathrm{mg}$ of vitamin B1 and $0.15 \mathrm{mg}$ of vitamin B6, $15 \mathrm{mg}$ of vitamin B9 (as a calcium folinate tablet) and $1000 \mathrm{IU}(25 \mu \mathrm{g}) /$ day of cholecalciferol (vitamin D). The cumulative weekly dose of elemental iron administered was $700 \mathrm{mg}$ (less than the maximum dose indicated by the manufacturer, which corresponded to $1000 \mathrm{mg}$ /week).

Intravenous ferric carboxymaltose previously demonstrated improved symptoms, functional capacity and quality of life in HF patients, even in the absence of anaemia, in the FAIR-HF clinical trial [10]. Subsequent clinical trials re-confirmed the benefits of intravenous ferric carboxymaltose, with improvements in exercise capacity in the EFFECT$\mathrm{HF}$ trial [26] and a reduced risk of hospitalizations for HF exacerbation in the CONFIRM-HF trial [27] and in the recently published AFFIRM-AHF clinical trial [28].

The control group consisted of a cohort of elderly female patients $(n=15$; age $76.1 \pm 11$ y.o.) with the same inclusion criteria, except that the levels of albumin and vitamins were near the lower limits but still within the normal range. This group re- 
ceived only standard iron therapy without supplementation. The baseline mean clinical biochemical data from two cohorts are summarised in Table 1.

Table 1. Comparison of the baseline antropometric and clinical biochemical data from patients who received integrated therapy and iron standard therapy (control). Note that patients that received the iron standard therapy had nutritional parameters (albumin and vitamins) close to the lower limit of the normal range. TIBC, Total Iron Binding Capacity; CRP, C-reactive protein; NT-proBNP, B-type natriuretic peptide; LVEF, Left Ventricular Ejection Fraction; BMI, body mass index and CVP, Central venous pressure.

\begin{tabular}{|c|c|c|c|}
\hline & $\begin{array}{l}\text { Integrated Therapy } \\
\qquad(n=15)\end{array}$ & $\begin{array}{l}\text { Standard Therapy } \\
\qquad(n=15)\end{array}$ & Normal Value \\
\hline Age (y.o) & $78.3 \pm 8.5$ & $76.1 \pm 11$ & - \\
\hline BMI & $26.9 \pm 1.85$ & $25.5 \pm 1.91$ & $<25$ \\
\hline Haemoglobin (g/dL) & $10.2 \pm 0.8$ & $10.37 \pm 0.91$ & $>11.5$ \\
\hline Creatinine $(\mathrm{mg} / \mathrm{dL})$ & $1.06 \pm 0.25$ & $1.02 \pm 0.19$ & $0,5-1,1$ \\
\hline Albumin (g/dL) & $3.31 \pm 0.37$ & $3.55 \pm 0.08$ & $>3.5$ \\
\hline Ferritin $(\mathrm{ng} / \mathrm{mL})$ & $73.73 \pm 38.81$ & $94.80 \pm 40.76$ & $15-200$ \\
\hline Sideraemia (serum iron) $(\mu \mathrm{g} / \mathrm{dL})$ & $36.07 \pm 6.85$ & $33.72 \pm 9.33$ & $50-150$ \\
\hline Transferrin saturated $(\%)$ & $14.33 \pm 4.24$ & $12.88 \pm 2.18$ & $20-45$ \\
\hline Transferrin total (TIBC) ( $\mu \mathrm{g} / \mathrm{dL})$ & $228.53 \pm 48.09$ & $224.33 \pm 50.0$ & $180-380$ \\
\hline Vitamin B9 (ng/mL) & $2.32 \pm 0.35$ & $3.13 \pm 0.20$ & 3 \\
\hline $1,25-\mathrm{OH}$ Vitamin D (pg/mL) & $17.73 \pm 4.23$ & $21.87 \pm 2.25$ & $21-100$ \\
\hline $\mathrm{CRP}(\mathrm{mg} / \mathrm{dL})$ & $10.67 \pm 2.43$ & $10.82 \pm 2.70$ & $<5$ \\
\hline NT-proBNP (pg/mL) & $2449.2 \pm 2048.69$ & $2650.27 \pm 2177.65$ & $<450$ \\
\hline $\operatorname{LVEF}(\%)$ & $54 \pm 6$ & $56 \pm 5$ & $>50$ \\
\hline $\mathrm{CVP}(\mathrm{mmHg})$ & $5.5 \pm 1.08$ & $5.73 \pm 1.05$ & $<8$ \\
\hline
\end{tabular}

\section{Statistics}

Data are expressed as the mean \pm standard deviation. A two-tailed paired Student's $t$-test was used to compare the data before (T0) and after (T30) the therapy within each group. Increments by treatments between the two groups were evaluated by the unpaired two-tailed Welch's $t$-test. The $p$-value $<0.05$ was considered significant.

\section{Results}

The baseline and postintervention clinical biochemical data of the patients reciving integrated therapy are summarised in Table 2. Increased levels of sideraemia (serum iron), ferritin and saturated transferrin were observed in both groups (Tables 2 and 3). However, when compared to the basal levels, only the experimental group receiving intravenous iron therapy plus integrated therapy demonstrated a significant increase in the haemoglobin concentration (Figure 4A,B), while no modification was observed in the group receiving the standard iron therapy only (see Table 3 and Figure 4C,D). The comparisons of the modifications of the biochemical data for the two groups of patients (postvalue minus prevalue) are summarised in Table 4.

Table 2. Clinical biochemical data before (baseline) and after (30 days) integrated therapy. TIBC, Total Iron Binding Capacity. Two-tailed paired Student's $t$-test. ${ }^{*} p<0.05$.

\begin{tabular}{ccccc}
\hline Integrated Therapy & Baseline & 30 Days & $\boldsymbol{t}$ & $\boldsymbol{p}$ \\
\hline Haemoglobin $(\mathrm{g} / \mathrm{dL})$ & $10.1 \pm 0.76$ & $11.06 \pm 0.83^{*}$ & 10.94 & 0.000 \\
Ferritin $(\mathrm{ng} / \mathrm{mL})$ & $73.73 \pm 38.81$ & $390.93 \pm 196.4^{*}$ & 6.89 & 0.000 \\
Sideraemia-serum iron $(\mu \mathrm{g} / \mathrm{dL})$ & $36.07 \pm 6.85$ & $81.93 \pm 16.84^{*}$ & 7.59 & 0.000 \\
Transferrin saturated $(\%)$ & $14.33 \pm 4.24$ & $51.28 \pm 10.24^{*}$ & 13.35 & 0.000 \\
Transferrin total $(\mathrm{TIBC})(\mu \mathrm{g} / \mathrm{dL})$ & $228.53 \pm 48.09$ & $253.0 \pm 50.37^{*}$ & 6.14 & 0.000 \\
\hline
\end{tabular}


Table 3. Clinical biochemical data before (baseline) and after (30 days) the standard iron therapy. TIBC, Total Iron Binding Capacity. Two-tailed paired Student's $t$-test. ${ }^{*} p<0.05$.

\begin{tabular}{ccccc}
\hline Standard Therapy & Baseline & 30 Days & $\boldsymbol{t}$ & $\boldsymbol{p}$ \\
\hline Haemoglobin $(\mathrm{g} / \mathrm{dL})$ & $10.37 \pm 0.88$ & $10.66 \pm 0.87$ & 0.834 & 0.412 \\
Ferritin $(\mathrm{ng} / \mathrm{mL})$ & $94.80 \pm 39.29$ & $631.47 \pm 280^{*}$ & 7.99 & 0.000 \\
Sideraemia-serum iron $(\mu \mathrm{g} / \mathrm{dL})$ & $33.72 \pm 9.07$ & $109.0 \pm 27.62^{*}$ & 10.242 & 0.000 \\
Transferrin saturated $(\%)$ & $12.88 \pm 2.1$ & $56.23 \pm 9.5^{*}$ & 20.368 & 0.000 \\
Transferrin total $(\mathrm{TIBC})(\mu \mathrm{g} / \mathrm{dL})$ & $224.33 \pm 48.18$ & $218.33 \pm 58.35$ & 1.828 & 0.089 \\
\hline
\end{tabular}

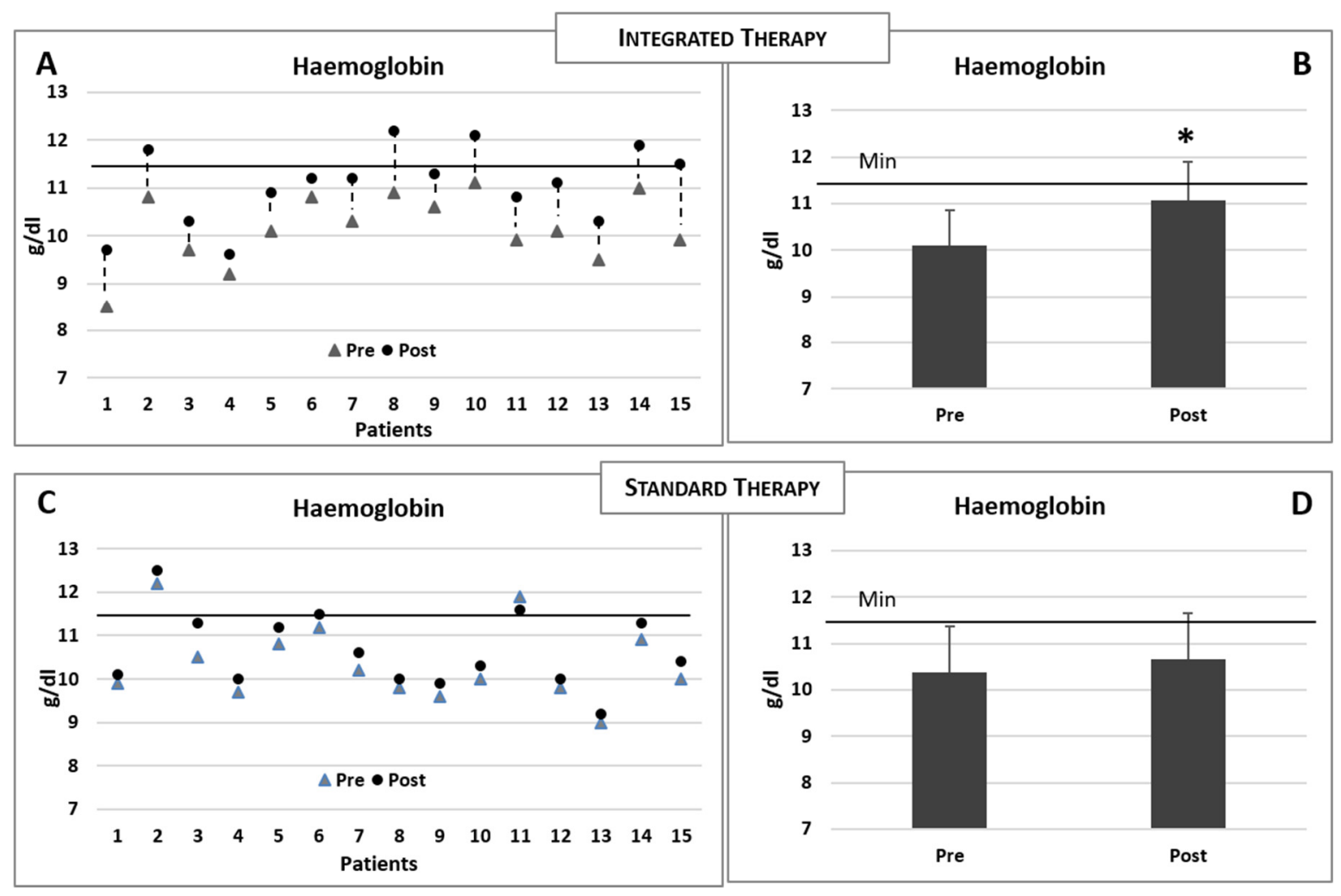

Figure 4. (A,B) Changes in the haemoglobin concentrations in each patient consequent to the integrated therapy. Histogram shows the mean $( \pm \mathrm{sd})$ concentrations of haemoglobin before (pre) and after (post) the integrated therapy. (C,D) Changes in the haemoglobin concentrations in each patient consequent to the iron standard therapy. Histogram shows the mean ( \pm sd) concentrations of haemoglobin before and after the iron standard therapy. The black line indicates the minimum reference value. Two-tailed paired Student's $t$-test. ${ }^{*} p<0.05$.

Table 4. Comparisons of the biochemical data (postvalue minus prevalue for each patient) between the standard therapy and integrated therapy (mean \pm st. dev.). TIBC, Total Iron Binding Capacity. Unpaired two-tailed Welch's $t$-test. * $p<0.05$.

\begin{tabular}{ccccc}
\hline & Standard Therapy & Integrated Therapy & $\boldsymbol{t}$ & $\boldsymbol{p}$ \\
\hline Haemoglobin & $0.29 \pm 0.22$ & $0.90 \pm 0.32^{*}$ & 6.08 & 0.000 \\
Ferritin & $536.67 \pm 260.06$ & $317.20 \pm 178.16^{*}$ & 2.696 & 0.012 \\
Sideraemia-serum iron & $75.28 \pm 28.46$ & $45.87 \pm 23.39 *$ & 3.092 & 0.005 \\
Transferrin saturated & $45.35 \pm 8.24$ & $36.95 \pm 10.71^{*}$ & 2.408 & 0.023 \\
Transferrin total (TIBC) & $13.2 \pm 27.97$ & $24.47 \pm 15.44$ & 1.366 & 0.186 \\
\hline
\end{tabular}

\section{Discussion and Conclusions}

The incidence of anaemia (32\%) is common in HF patients, with concurrent iron and folate deficiencies reported in $43 \%$ of anaemic patients and in $15 \%$ of nonanaemic 
patients [29]. Currently, the standard therapy of anaemia is primarily based on the supplementation of iron, with or without erythropoietin for hematopoiesis stimulation. Previous randomised, controlled studies with intravenous iron in HF patients reported that haemoglobin increased after four or six months of treatment $[7,10,30,31]$. Indeed, if a deficiency of fundamental molecules (such as amino acids and vitamins) results in the lack of heme synthesis, iron supplementation alone will not lead to a proportional hemoprotein increase and of $\mathrm{Hb}$ in primis. In addition, an isolated increase in soluble iron ions, without any accompanying augmentation in heme, could favor the persistence of oxidative stress (via Fenton/Haber-Weiss reactions), chronic inflammation and autophagy [32]. The mode of iron supplementation also appears to be important, as oral supplementation was ineffective in improving the exercise capacity in HF patients with reduced ejection fraction and iron deficiency [33].

After the integrated therapy, we observed improvements of ferritin in both groups, but this was more elevated in patients who received the standard therapy. Iron, although it is an essential micronutrient, is potentially toxic for biological systems, since it generates free radicals by interconversions between ferrous $\left(\mathrm{Fe}^{2+}\right)$ and ferric $\left(\mathrm{Fe}^{3+}\right)$ forms. However, existing regulatory processes in the body are efficacious in reducing the toxicity of iron, even in response to an overload [34]. Interestingly, patients receiving the integrated therapy had lower ferritin concentrations than those receiving the standard therapy. This suggests that the use of iron for the synthesis of haemoglobin was rapidly promoted and much more effective in the integrated therapy, thus also limiting the possible toxic effects of iron deposits.

Based on these preliminary data showing a rapid escalation in the haemoglobin level (within 30 days after the interventions aimed at increasing both iron and heme), we propose that a more effective approach to treating heme synthesis (including anaemia) in CD must consider not only the iron availability but, also, integrate a therapeutic strategy that counteracts the catabolic drives and promotes protein syntheses. Therefore, the standard intravenous or oral iron supplementation should incorporate also a supply of specific mixtures of EAAs and vitamins involved in the biochemical pathway of heme synthesis, as illustrated in Figure 5. Consequently, the careful evaluation of either the nutritional status of patients and the presence of catabolism or impairement of the availability of molecules involved in heme synthesis, as well as their integration, must therefore be the first step of an effective individualised therapeutic intervention aimed at correcting the state of anaemia in patients with CD such as CHF. Our therapeutical approach based on biochemical data should be confirmed in a large-scale clinical trial.

INTEGRATED THERAPY

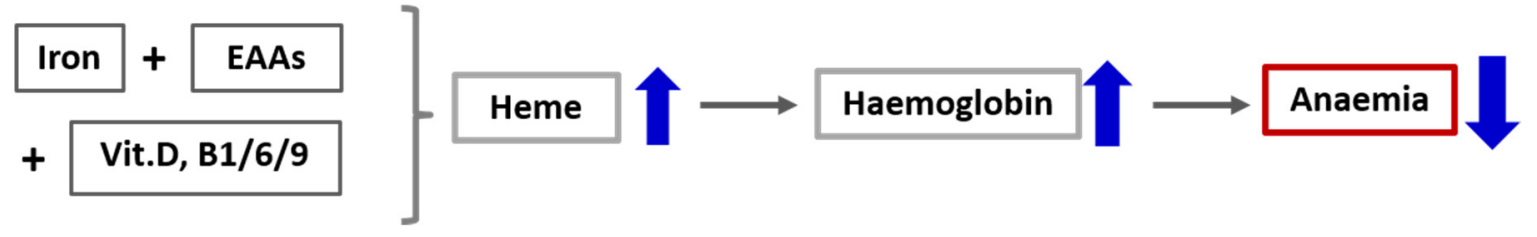

Figure 5. Schematic representation of the effects of integrated therapy on the containment of anaemia.

The main messages:

- In chronic hypercatabolic diseases (such as CHF), the metabolism of iron and the heme protein is markedly impaired, inducing anaemia and the likely impairment of many other hemoproteins involved in the essential metabolic pathways.

- Heme is the metabolically active part of haemoglobin. It is characterised by the presence of iron atoms linked to tetrapyrrole groups.

- Many other important biologically active molecules, named hemoproteins (including $\mathrm{Hb}$ ), contain heme as the metabolically active part, with the surrounding proteins (as globin molecules) containing a large number of different amino acids. 
- The maintenance of an adequate blood concentration of both iron and heme is fundamental for proper function of the heme-containing enzymes.

- In patients with anaemia and chronic hypercatabolic diseases, the correction of deficiencies in iron, as well as the metabolic substrates required for all hemoproteins, is essential for proper treatment.

\begin{abstract}
Author Contributions: E.P. and G.C. wrote the manuscript; these authors contributed equally to this work. G.C. and C.R. arranged the text, the figures and the references. F.S.D., R.A., T.S. and C.C.-S. reviewed the text. T.S. and C.C.-S. revised the English language. All authors conceptualised the topic and discussed the literature data. All authors approved the final version of the manuscript and ensure the accuracy of the work and intellectual content. All authors have read and agreed to the published version of the manuscript.
\end{abstract}

Funding: This study was supported by local funds to CG.

Institutional Review Board Statement: Not applicable.

Informed Consent Statement: Informed consent was obtained from all subjects involved in the study.

Data Availability Statement: The data presented in this study are available on request from the corresponding author. The data are not publicly available due to privacy reason.

Conflicts of Interest: The authors declare that the research was conducted in the absence of any commercial or financial relationships that could be construed as a potential conflict of interests.

\title{
References
}

1. World Health Organization. Noncommunicable diseases. Fact Sheet. January 2015. Available online: https://www.who.int/ topics/noncommunicable_diseases/factsheets/en/ (accessed on 5 April 2016).

2. Bernell, S.; Howard, S.W. Use your words carefully: What is a chronic disease? Front. Public Health 2016, 4, 159. [CrossRef] [PubMed]

3. Pasini, E.; Aquilani, R.; Dioguardi, F.S.; D'Antona, G.; Gheorghiade, M.; Taegtmeyer, H. Hypercatabolic syndrome: Molecular basis and effects of nutritional supplements with amino acids. Am. J. Cardiol. 2008, 101, 11E-15E. [CrossRef] [PubMed]

4. Aquilani, R.; Maestri, R.; Boselli, M.; Achilli, M.P.; Arrigoni, N.; Bruni, M.; Dossena, M.; Verri, M.; Buonocore, D.; Pasini, E.; et al. The relationship between plasma amino acids and circulating albumin and haemoglobin in postabsorptive stroke patients. PLoS ONE 2019, 14, e0219756. [CrossRef] [PubMed]

5. Comín-Colet, J.; Enjuanes, C.; González, G.; Torrens, A.; Cladellas, M.; Meroño, O.; Ribas, N.; Ruiz, S.; Gómez, M.; Verdú, J.M.; et al. Iron deficiency is a key determinant of health-related quality of life in patients with chronic heart failure regardless of anaemia status. Eur. J. Heart Fail. 2013, 15, 1164-1172. [CrossRef] [PubMed]

6. Klip, I.T.; Comin-Colet, J.; Voors, A.A.; Ponikowski, P.; Enjuanes, C.; Banasiak, W.; Lok, D.J.; Rosentryt, P.; Torrens, A.; Polonski, L.; et al. Iron deficiency in chronic heart failure: An international pooled analysis. Am. Heart J. 2013, 165, 575-582.e3. [CrossRef] [PubMed]

7. van Veldhuisen, D.; Anker, S.; Ponikowski, P.; Macdougall, I.C. Anemia and iron deficiency in heart failure: Mechanisms and therapeutic approaches. Nat. Rev. Cardiol. 2011, 8, 485-493. [CrossRef]

8. Corsetti, G.; Chen-Scarabelli, C.; Romano, C.; Pasini, E.; Dioguardi, F.S.; Onorati, F.; Knight, R.; Patel, H.; Saravolatz, L.; Faggian, G.; et al. Autophagy and oncosis/necroptosis are enhanced in cardiomyocytes from heart failure patients. Med. Sci. Monit. Basic Res. 2019, 25, 33-44. [CrossRef]

9. Sîrbu, O.; Floria, M.; Dascalita, P.; Stoica, A.; Adascalitei, P.; Sorodoc, V.; Sorodoc, L. Anemia in heart failure—From guidelines to controversies and challenges. Anatol. J. Cardiol. 2018, 20, 52-59. [CrossRef]

10. Anker, S.D.; Colet, J.C.; Filippatos, G.; Willenheimer, R.; Dickstein, K.; Drexler, H.; Lüscher, T.F.; Bart, B.; Banasiak, W.; Niegowska, J.; et al. Ferric carboxymaltose in patients with heart failure and iron deficiency. N. Engl. J. Med. 2009, 361, 2436-2448. [CrossRef]

11. Poulos, T.L. Heme enzyme structure and function. Chem. Rev. 2014, 114, 3919-3962. [CrossRef]

12. Pasini, E.; Dioguardi, F.S. Iron supplementation in the cardiorenal anaemia syndrome: A global metabolic approach. Eur. J. Heart Fail. 2012, 14, 1429. [CrossRef] [PubMed]

13. Richardson, D.R.; Ponka, P. The molecular mechanisms of the metabolism and transport of iron in normal. and neoplastic cells. Biochim. Biophys. Acta 1997, 1331, 1-40. [CrossRef]

14. Layer, G.; Reichelt, J.; Jahn, D.; Heinz, D.W. Structure and function of enzymes in heme biosynthesis. Protein Sci. 2010, 19, 1137-1161. [CrossRef] [PubMed]

15. Lonsdale, D. A review of the biochemistry, metabolism and clinical benefits of thiamin(e) and its derivatives. Evid. Based Complement Alternat. Med. 2006, 3, 49-59. [CrossRef] [PubMed]

16. Parra, M.; Stahl, S.; Hellmann, H. Vitamin $B_{6}$ and its role in cell metabolism and physiology. Cells 2018, 7, 84. [CrossRef]

17. Bailey, L.B.; Gregory, J.F. Folate metabolism and requirements. J. Nutr. 1999, 129, 779-782. [CrossRef] 
18. Smith, E.M.; Tangpricha, V. Vitamin D and anemia: Insights into an emerging association. Curr. Opin. Endocrinol. Diabetes Obes. 2015, 22, 432-438. [CrossRef]

19. D'Antona, G.; Ragni, M.; Cardile, A.; Tedesco, L.; Dossena, M.; Bruttini, F.; Caliaro, F.; Corsetti, G.; Bottinelli, R.; Carruba, M.O.; et al. Branched-chain amino acid supplementation promotes survival and supports cardiac and skeletal muscle mitochondrial biogenesis in middle-aged mice. Cell Metab. 2010, 12, 362-372. [CrossRef]

20. Corsetti, G.; Pasini, E.; D’Antona, G.; Nisoli, E.; Flati, V.; Assanelli, D.; Dioguardi, F.S.; Bianchi, R. Morphometric changes induced by amino acid supplementation in skeletal and cardiac muscles of old mice. Am. J. Cardiol. 2008, 101, 26E-34E. [CrossRef]

21. Rondanelli, M.; Aquilani, R.; Verri, M.; Boschi, F.; Pasini, E.; Perna, S.; Faliva, A.; Condino, A.M. Plasma kinetics of essential amino acids following their ingestion as free formula or as dietary protein components. Aging Clin. Exp. Res. 2017, 29, 801-805. [CrossRef]

22. Chung, J.; Bauer, D.E.; Ghamari, A.; Nizzi, C.P.; Deck, K.M.; Kingsley, P.D.; Yie, Y.Y. The mTORC1/4E-BP pathway coordinates hemoglobin production wit leucin availability. Sci. Signal. 2015, 8, ra34. [CrossRef] [PubMed]

23. Birukou, I.; Schweers, R.L.; Olson, J.S. Distal histidine stabilizes bound $\mathrm{O}_{2}$ and acts as a gate for ligand entry in both subunits of adult human hemoglobin. J. Biol. Chem. 2010, 285, 8840-8854. [CrossRef] [PubMed]

24. Vera-Aviles, M.; Vantana, E.; Kardinasari, E.; Koh, N.L.; Latunde-Dada, G.O. Protective role of histidine supplementation against oxidative stress damage in the management of anemia of chronic kidney disease. Pharmaceuticals 2018, 11, 111. [CrossRef] [PubMed]

25. Blancquaert, L.; Everaert, I.; Missinne, M.; Baguet, A.; Stegen, S.; Volkaert, A.; Petrovic, M.; Vervaet, C.; Achten, E.; DE Maeyer, M.; et al. Effects of histidine and a-alanine supplementation on human muscle carnosine storage. Med. Sci. Sports Exerc. 2017, 49, 602-609. [CrossRef] [PubMed]

26. van Veldhuisen, D.J.; Ponikowski, P.; van der Meer, P.; Metra, M.; Böhm, M.; Doletsky, A.; Voors, A.A.; Macdougall, I.C.; Anker, S.D.; Roubert, B.; et al. Effect of ferric carboxymaltose on exercise capacity in patients with chronic heart failure and iron deficiency. Circulation 2017, 136, 1374-1383. [CrossRef] [PubMed]

27. Ponikowski, P.; van Veldhuisen, D.J.; Comin-Colet, J.; Ertl, G.; Komajda, M.; Mareev, V.; McDonagh, T.; Parkhomenko, A.; Tavazzi, L.; Levesque, V.; et al. Beneficial effects of long-term intravenous iron therapy with ferric carboxymaltose in patients with symptomatic heart failure and iron deficiency. Eur. Heart J. 2015, 36, 657-668. [CrossRef]

28. Ponikowski, P.; Kirwan, B.A.; Anker, S.D.; McDonagh, T.; Dorobantu, M.; Drozdz, J.; Fabien, V.; Filippatos, G.; Göhring, U.M.; Keren, A.; et al. Ferric carboxymaltose for iron deficiency at discharge after acute heart failure: A multicentre, double-blind, randomised, controlled trial. Lancet 2020, 396, 1895-1904. [CrossRef]

29. de Silva, R.; Rigby, A.S.; Witte, K.K.A.; Nikitin, N.P.; Tin, L.; Goode, K.; Bhandari, S.; Clark, A.L.; Cleland, J.G.F. Anemia, renal dysfunction, and their interaction in patients with chronic heart failure. Am. J. Cardiol. 2006, 98, 391-398. [CrossRef]

30. Toblli, J.E.; Lombraña, A.; Duarte, P.; Di Genarro, F. Intravenous iron reduces NT-pro-brain natriuretic peptide in anemia patients with chronic heart failure and renal insufficiency. J. Am. Coll. Cardiol. 2007, 50, 1657-1665. [CrossRef]

31. Okonko, D.O.; Grzeslo, A.; Witkowski, T.; Mandal, A.K.J.; Slater, R.M.; Roughton, M.; Foldes, G.; Thum, T.; Majda, J.; Banasiak, W.; et al. Effect of intravenous iron sucrose on exercise tolerance in anemic and nonanemic patients with chronic heart failure and iron deficiency. FERRIC-HF: A randomized, controlled, observer-blinded trial. J. Am. Coll. Cardiol. 2008, 51, 103-312. [CrossRef]

32. Stohs, S.; Bagchi, D. Oxidative mechanisms in the toxicity of metal ions. Free Radic. Biol. Med. 1995, 18, 321-336. [CrossRef]

33. Lewis, G.D.; Malhotra, R.; Hernandez, A.F.; McNulty, S.E.; Smith, A.; Felker, G.M.; Tang, W.H.W.; LaRue, S.J.; Redfield, M.M.; Semigran, M.J.; et al. Effect of oral iron repletion on exercise capacity in patients with heart failure with reduced ejection fraction and iron deficiency: The IRONOUT HF randomized clinical trial. JAMA 2017, 317, 1958-1966. [CrossRef] [PubMed]

34. Eid, R.; Arab, T.T.N.; Greenwood, M.T. Iron mediated toxicity and programmed cell death: A review and a re-examination of existing paradigms. Biochim. Biophys. Acta Mol. Cell Res. 2017, 1864, 399-430. [CrossRef] [PubMed] 